\title{
IMPROVEMENT OF FILLER-MATRIX INTERACTIONS IN POLYPROPYLENE/MONTMORILLONITE NANOCOMPOSITES BY USING IRRADIATED POLYPROPYLENE
}

\author{
Fatma Zengin $^{1}$, Tahsin Çağlayan ${ }^{1}$, Semra Ide ${ }^{2}$, Olgun Güven ${ }^{1, *}$ \\ Hacettepe University, Departments of Chemistry ${ }^{1}$ and Physics Engineering ${ }^{2}$ \\ Beytepe, 06800, Ankara, Turkey
}

*Corresponding author, guven@hacettepe.edu.tr

\begin{abstract}
In the preparation of polymer-clay nanocomposites the chemical incompatibility between the clay surface and polyolefins can be overcome by using clays organically modified with short chain organic cations. The compatibility can be further enhanced by using functionalized polymer that wets the clay surface while being miscible with the non-polar polymer matrix. In this work we tried to modify the host polymer polypropylene (PP) by irradiating it with gamma-rays in air knowing that it undergoes oxidation and chain scission simultaneously. Thus lower molecular weight PP with highly polar surface due to oxidation can be expected to play double role of clay modifier and functional compatibilizer. This has been observed to be the case. Finely ground PP granules were irradiated in air in a ${ }^{60} \mathrm{Co} \gamma$-irradiator at the dose rate of $0.08 \mathrm{kGy} / \mathrm{h}$ (low dose rate to enhance oxidation) to 5,10 , and $20 \mathrm{kGy}$ total doses. The extent of oxidation and change in molecular weight were determined by ATR-FTIR and Melt Flow Rate measurements respectively. PP/MMT nanocomposites were prepared by using $20 \% \gamma-\mathrm{PP}, 1-5 \% \mathrm{MMT}$ and pristine PP to make up the total 100 in a torque rheometer. Maleated PP was also used in similar quantities to compare the effectiveness of $\gamma$-PP as a compatibilizing agent. Nanocomposites prepared with $10 \mathrm{kGy}$ irradiated PP was found to show optimum mechanical properties among all formulations, with $26 \%$ increase in Emodulus and $10 \%$ increase in tensile strength as compared to pristine PP. Ternary PP nanocomposites were characterized by XRD, SAXS and PALS studies.
\end{abstract}




\section{INTRODUCTION}

In polymer nanocomposites nanosized inorganic fillers are dispersed in a polymer matrix improving various properties of the base polymer significantly. The addition of nanoclays as filler to a polymer matrix has been proven to bring significant improvement in the mechanical properties, thermal stability, fire resistance and gas barrier properties of starting polymeric materials [1].

The dispersion of layered silicates in thermoplastic matrices has been of great interest in the polymer industry. This is because nano-layer reinforced polymers can exhibit greatly enhanced properties mentioned above at very low weight fractions of less than $10 \%$. In fact it is interesting to note that polymer/clay nanocomposites did not emerge from academic circles but from the commercial interest of Toyota Company by using Nylon-6/clay nanocomposites in their cars for the first time in 1990 to produce timing belt covers [2]. Since these pioneering works various types of clay have been modified and extensively used in polymer nanocompositeswith the anticipation of their use by the industry[3].

The chemical incompatibility between the clay surface and polyolefins however pose significant challenges in the production of polymer nanocomposites with thermoplastic matrices. Because most thermoplastic polymers are hydrophobic and are not compatible with hydrophilic clays. The chemical incompatibility can be overcome by organically modifying clays with short-chain organic cations. The compatibility can be further enhanced by using a fuctionalized polymer that wets the clay surface while being miscible with the non-polar polymer matrix. Maleated polyolefins are frequently used to compatibilize the bulk polymer with the clay $[4,5]$.

Polypropylene (PP) is one of the most widely used polyolefins for a number of applications such as automotive, construction, packaging because of its overall balanced properties and cost attractiveness. Further improvement of its mechanical and thermal properites can be achieved by preparing its nanocomposites using clays. Development of PP/clay nanocomposites has therefore attracted great interest both from academia and industry[6]. Homogeneous dispersion of silicate layers of clay with their polar structures in non-polar PP matrix would not be realized easily due to the incompatibility of the two, namely filler and the matrix. Even when organically modified clay has been used with PP the dispersion was not so successful unless some compatibilizers are used [7]. These compatibilizers should contain 
sufficient polar groups that would interact with the silicate layers as well as easy mixing with the bulk PP.

The polar functional groups of PP-g-MA interact with the edges of polar layers of nanoclay facilitating the diffusion and interaction of polymer chains in the clay galleries. Although maleic anhydride grafted polypropylene provides intercalation between the bulk PP and clay, higher amounts of this compatilization agent may alter the mechanical properties of the composite adversely. This is because of the lower molecular weight of PP-g-MA. Large amounts of low or modest molecular weight maleated PP will lower the mechanical properties of the final composite material drastically [4,8]. It is therefore important to investigate the effect of smaller compatibilizer loading on the properties of the composite. In order to prepare $\mathrm{PP} /$ clay nanocomposites with optimum mechanical properties, many parameters like type and amount of clay, molecular weight and amount of PP-g-MA and type of PP should be considered.

In some studies ionizing radiation either as gamma rays or accelerated electrons has been used to modify the structures of either clays or polymers to enhance their compatibility with the matrix polymer. Thakur et al. [9] modifed atactic polypropylene at room temperature with high energy electrons at $200 \mathrm{kGy}$ in air under reactive conditions. The modified/oxidized aPP was used as a compatibilizer together with organically modified MMT in pristine aPP resulting with good dispersion of the modified clay in aPP matrix. In another work [10] unmodified MMT was interacted with a charged monomer in the presence of water and then irradiated with gamma rays to achieve in-situ polymerization of the monomer in between the silicate layers. Thus d-spacing of $1.27 \mathrm{~nm}$ of the pristine clay was increased to $2.29 \mathrm{~nm}$ allowing the formation of intercalated structures with improvement in the mechanical properties by about $50 \%$.

In this work instead of using organo-modified montmorillonite (MMT), or using a compatibilizer we have attempted to modify the host polymer isotactic polypropylene (PP) by irradiating it with gamma rays in air. It is very well known that when PP is irradiated with ionizing radiation in air it undergoes oxidation and extensive chain scission [11]. The lower molecular weight PP with highly polar surface due to radiation-induced oxidation has been anticipated to play the double role of clay modifier and compatibilizer. In order to elucidate the anticipated compatibilization effect of radiation degraded/oxidized PP, oxidized-only PP was also used as compatibilizer by using ozone treated PP under identical preparation conditions of PP nanocomposites. 


\section{EXPERIMENTAL}

\section{Materials}

Commercial polypropylene (PP) sample PETOPLEN MH 418 obtained from PETKIM company Turkey with Melt Flow Rate (MFR) value of 4-6 g/10 min measured at $2.16 \mathrm{~kg} / 230$ ${ }^{\circ} \mathrm{C}$ was used in the preparation of nanocomposites. Unmodified Na-montmorillonite (MMT) with a cation exchange capacity value of about $145 \mathrm{meq} / 100 \mathrm{~g}$ was purchased from Nanomer/PGV company. To compare the compatibilizing effect of irradiated PP in the nanocomposite, commercially available PP compatibilizer namely, Polypropylene-g-Maleic Anhydride (PP-g-MA) obtained from Exxelor PO with the code of MAPP was used.

\section{Preparation of Nanocomposites}

Finely ground PP granules were irradiated in air in a GammaCell $220{ }^{60}$ Co gamma irradiator at a dose rate of $0.08 \mathrm{kGy} / \mathrm{h}$ determined by Fricke dosimetry to three different total absorbed doses of 5, 10 and $20 \mathrm{kGy}$. By irradiating in air and at low dose rate, PP was simultaneously oxidized and extensively chain scissioned which was determined by measuring its MFR. $\mathrm{PP} /$ compatibilizer/MMT ternary systems were prepared by using $20 \%$ by weight [7] the gamma irradiated PP ( $\gamma$-PP) as compatibilizer, 1-5\% MMT and pristine PP to make up the total 100 by using a torque rheometer. Additionally another ternary blend was prepared from 20\% PP-g-MA, 1-5\% MMT and pristine PP to compare the compatibility induced by ( $\gamma$-PP) and (PP-g-MA) and finally PP oxidized by ozon treatment was also tested for its compatibilization action due to its highly oxidized hence polar character. PP nanocomposite sheets were prepared by heating/melting granules of ternary blends for 3 minutes at $190{ }^{\circ} \mathrm{C}$ and 150 bar by using a Brabender polystat 200T type heat press.

\section{Characterization of Properties}

From a practical point of view the most important property to be investigated to see the effect of modes of preparation of ternary blends is their mechanical properties. Stress-strain tests were carried out by using a universal mechanical testing device, ZWICK Z010 following the ASTM D638 standard. The number of samples tested for each data point given in Figs.1-3 is 5. 
The extent of oxidation of PP powder either due to irradiation or ozonation was determined by using a Nicolet iS10 Diamond ATR-FTIR spectrometer.

Melt Flow Rates (MFR) of original and irradiated and ozon treated PP samples were measured by using CEAST Modular Melt Flow Rate apparatus at $190{ }^{\circ} \mathrm{C}$ and $2.16 \mathrm{~kg}$ operational conditions.

XRD patterns were obtained by using a Japanese Rigaku D/Max-2200/PC X-ray diffractometer equipped with graphite mono-chromatized $\mathrm{CuK} \alpha$ radiation $(\lambda=0.15406 \mathrm{~nm})$. The scanning range was $2^{\circ}-15^{\circ}$ with a scanning rate of $2^{\%} / \mathrm{min}$.

The microstructures of nanocomposites were imaged by using a Tecnai G2F30 $(300 \mathrm{kV})$ Transmission Electron Microscopy (TEM). The samples for TEM were cut to $200 \mathrm{~nm}$ thick sections with a diamond knife microtome (Leica Microsystems, Model EMUC6 +EMFC6).

SAXS experiments were performed with a Kratky compact Hecus system equipped with a linear collimation system and X-ray tube with a $\mathrm{Cu}$ target $(\lambda=1.54 \AA)$. The generator was operated at a power of $2 \mathrm{~kW}(50 \mathrm{kV}$ and $40 \mathrm{~mA})$. SAXS measurements are possible in the system with a linear position-sensitive detector used with 1024 channel resolution. Distances between channels and the sample and detector are $54 \mu \mathrm{m}$ and $27.9 \mathrm{~cm}$, respectively. Scattering curves were measured in the q range of 0.04-0.5 $\AA^{-1}$ for SAXS. All SAXS profiles were measured during 600 seconds at room temperature.

The free volume holes generated during preparation of PP nanocomposites were determined by an ORTEC Positron Annihilation Lifetime Spectrometer (PALS) using $\sim 30 \mu \mathrm{Ci}{ }^{22} \mathrm{NaCl}$ as positron source in sandwich formation (sample-source-sample). PALS spectra were analysed by LT9 program available in the software of the system.

\section{RESULTS AND DISCUSSION}

In order to make a non-polar, hydrophobic polymer compatible with a filler of polar and hydrophilic properties it is necessary to modify either or both of them to impart the missing properties [12]. Commercially available organo-modified clays are being used extensively in the preparation of polymer/clay composites. If natural, unmodified clays are to be used then a polymeric compatibilizer with essentially very similar structure as that of bulk polymer is generally used in composite formulation. To introduce polarity into fully non-polar structures of polyolefins they are often grafted with maleic anhydride. In fact a commercially available 
PP-g-MA compatibilizer was also used in this work for the preparation of PP/MMT nanocomposite as a reference material.

It is very well know that the incompatibility of pure PP with unmodified MMT is due to its non-polar structure and very high molecular weight. By this argument we have assumed that if the molecular weight of PP can be significantly reduced and at the same time oxidized to impart highly polar character to otherwise fully hydrophobic structure, it may be anticipated that such low molecular weight and polar PP may act as a compatibilizer for the binary blend of PP/MMT. As the indicator of molecular weight, MFR values of PPs used in this work are measured and collected in Table 1 below:

Table1. MFR values of various forms of PPs used in this study

\begin{tabular}{|l|l|l|}
\hline Sample & Absorbed Dose (kGy) & MFR (g/10min) \\
\hline \multirow{4}{*}{$\begin{array}{l}\text { Gamma irradiated } \\
\text { PP }\end{array}$} & $0 \mathrm{kGy}$ & $2.10 \pm 0.05$ \\
\cline { 2 - 3 } & $5 \mathrm{kGy}$ & $10.65 \pm 4.42$ \\
\cline { 2 - 3 } & $10 \mathrm{kGy}$ & $32.12 \pm 4.79$ \\
\cline { 2 - 3 } & $20 \mathrm{kGy}$ & $41.80 \pm 4.86$ \\
\hline Ozonized PP & $360 \mathrm{~min}$ & $2.70 \pm 0.03$ \\
\hline PP-g-MA & & $40.26 \pm 3.08$ \\
\hline
\end{tabular}

The increasing MFR values with dose listed in Table 1 immediately reveals the fact that PP undergoes extensive degradation upon irradiation in air even at relatively low doses of 10 and $20 \mathrm{kGy}$. When PP is exposed to high energy radiation in the presence of air, the radicals generated by scissioning of $\mathrm{C}-\mathrm{C}$ bonds and abstraction of hydrogen combine with oxygen resulting with the formation of ketones, acids, hydroperoxides and alcohols, etc. [13].

The surface oxidation of polyolefins can also be achieved easily by treatment with ozone [14]. PP powders used in this work were exposed to ozone gas for different periods of time to obtain oxidized PP. ATR-FTIR was used to determine the level of oxidation induced by gamma irradiation and ozonation of PP powders. The main difference observed between the ATR-FTIR spectra (not shown here) of pristine and irradiated/ozonized PP is the appearance of a band with sharp peak at around $1730 \mathrm{~cm}^{-1}$ which indicates the presence of various oxygenated groups, mainly carbonyl. The intensity of this peak in absorbance mode was ratioed to that of the peak at $1455 \mathrm{~cm}^{-1}$ which is due to $\left(-\mathrm{CH}_{2}-\right)$ groups assumed not to be 
significantly affected from the changes. This ratio called "carbonyl index" is used to compare quantitatively the extent of oxidation by gamma irradiation and ozonation. We have observed that the same level of oxidation was achieved when PP was irradiated to $10 \mathrm{kGy}$ dose or ozonized for $360 \mathrm{~min}$. As can be seen from Table 1, MFR value of $360 \mathrm{~min}$ ozonized PP is slightly higher than that of unirradiated PP. This shows that although ozonation introduces significant amount of oxidized species on the PP chain, it has little adverse effect in terms of reducing its molecular weight. By using the ozonized PP as a compatibilizer in the ternary system we would therefore be able to see the contribution of polar structure of still high molecular weight PP on its compatibilization action if any. On the other hand it is important to note that by gamma irradiation to 10 and $20 \mathrm{kGy}$ doses the MFR value of irradiated PP becomes very close to that of the commercial compatibilizer PP-g-MA, while enriched highly with the oxygenated groups on the PP chain.

\section{Mechanical Tests}

Thus three different types of PP/MMT nanocomposites were prepared by using three compatibilizers, $\gamma$-PP, PP-g-MA and ozonized PP $\left(\mathrm{O}_{3}-\mathrm{PP}\right)$. First of all ternary blends of $\mathrm{PP} / \mathrm{MMT} / \gamma$-PP were prepared using PP irradiated to 5, 10 and $20 \mathrm{kGy}$ doses. E-modulus and tensile strength values of the blend prepared by using $10 \mathrm{kGy}$ irradiated PP showed the best results; hence $10 \mathrm{kGy}$ has been considered as the optimum dose to modify PP for nanocomposite application. Next step is to compare the mechanical properties of PP/MMT/ $\gamma$ PP-10kGy nanocomposite with PP/MMT nanocomposites prepared by using PP-g-MA and $\mathrm{O}_{3}$-PP with equal amounts of MMT. Figures 1, 2 and 3 show the changes in the Elastic Modulus, Tensile Strength and Elongation at Break values of the three nanocomposites as a function of clay loading (1-5\%). The nanocomposites prepared with $\gamma$-PP-10kGy compatibilizer showed significant improvements on Elastic Modulus and Tensile Strength values as compared to the nanocomposites prepared with the other two compatibilizers. Consequently the elongations at break values were inferior for the nanocomposite prepared with gamma-irradiated PP. The optimum mechanical properties were achieved at $1 \%$ loading of clay. The mechanical testes showed clearly that the use of radiation degraded/oxidized PP improved the interactions between unmodified clay and pristine PP. Various experimental techniques were used to explain this behaviour in the following sections. 


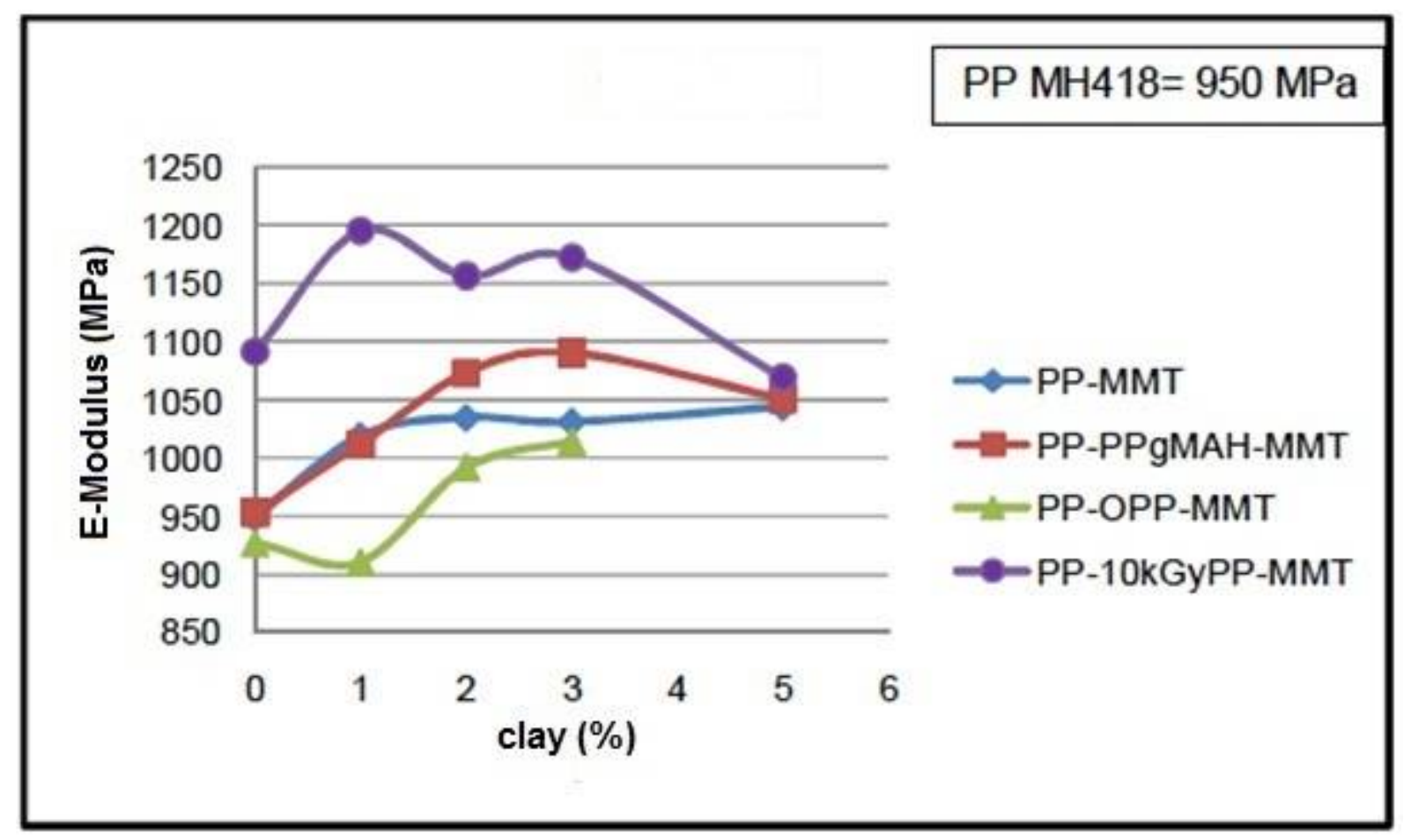

Figure 1. The change of elastic moduli of three different PP nanocomposites containing 20\% compatibilizer as a function of clay loading.

PP MH418=39,4 MPa
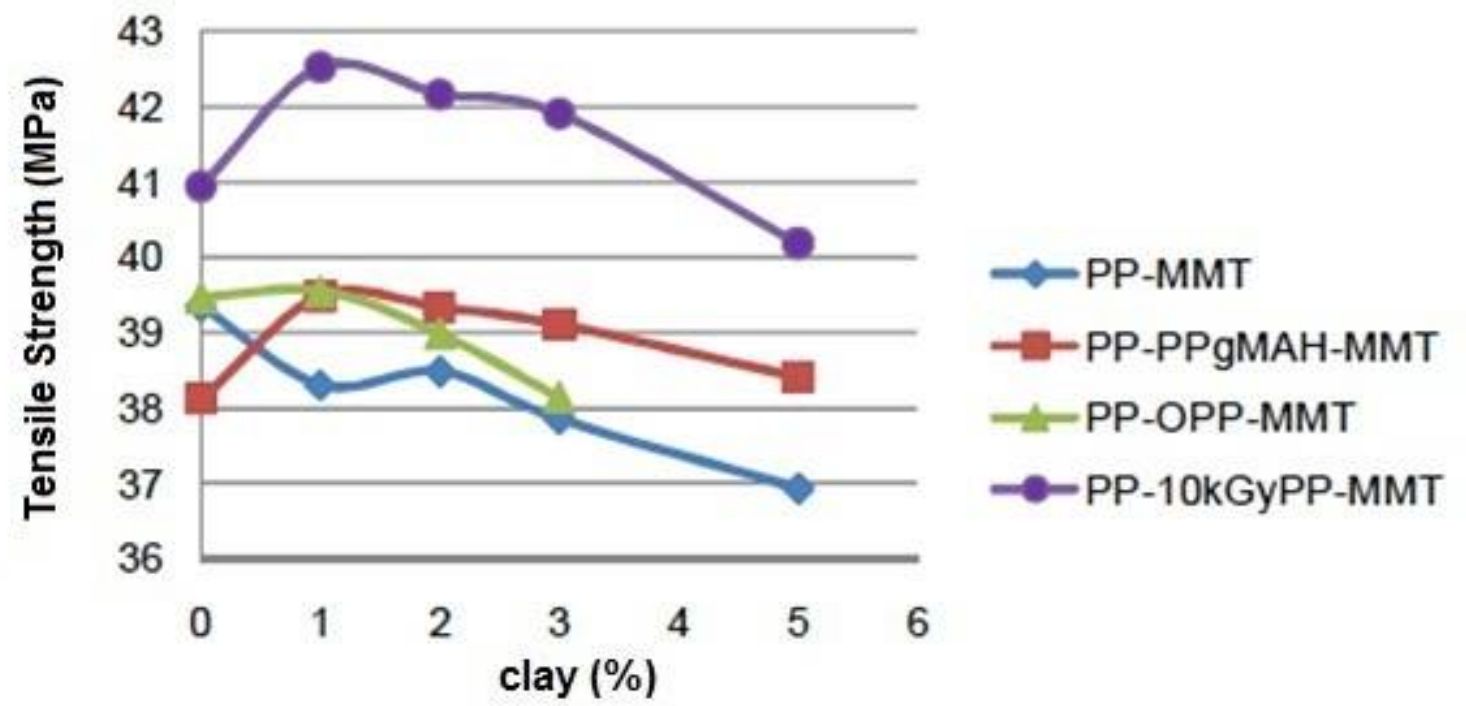
Figure 2. The change of tensile strength of three different PP nanocomposites containing 20\% compatibilizer as a function of clay loading.

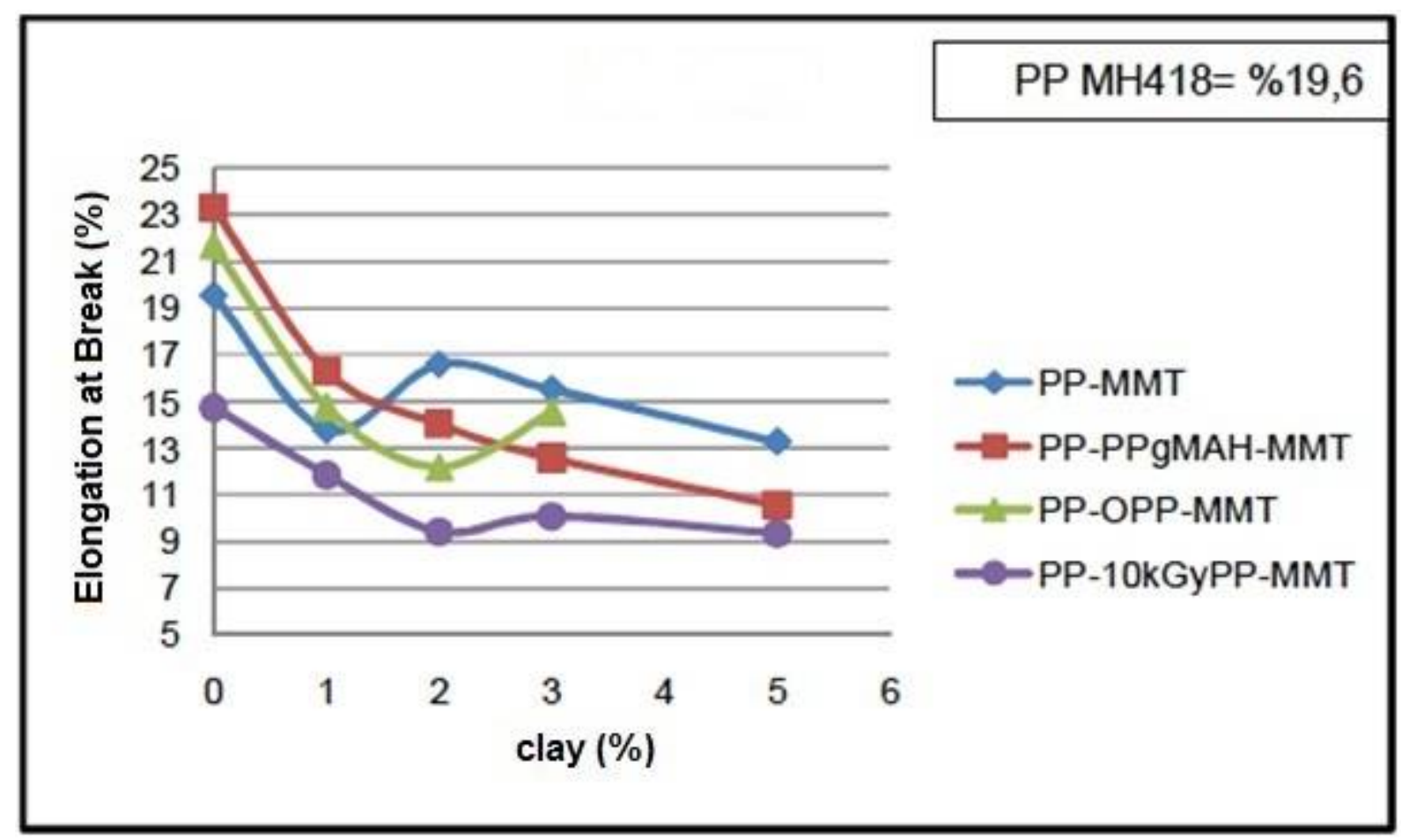

Figure 3. The change in elongation at break values of three different PP nanocomposites containing $20 \%$ compatibilizer as a function of clay loading.

\section{Determination of Sizes of Free Volume Holes}

Physical properties of polymers and polymer composites depend on the size and size distribution of free volume holes [15]. Positron Annihilation Lifetime Spectroscopy (PALS) was used to follow the changes taking place in the sizes of free volume holes in the PP nanocomposites prepared with different compatibilizers. The master PAL spectrum was deconvoluted to separate the contributions coming from amorphous and crystalline portions of the nanocomposites and respective free volume hole radii were calculated for these two domains. The life time of ortho-positronium in nanosecond determined by PALS measurements were used to calculate the free volume hole radii of the voids by using the following expression:

$$
\tau_{\text {o.Ps }}^{=}=0.5\left[1-\frac{R}{R+1.66}+\frac{1}{2 \pi} \sin \left(\frac{2 \pi R}{R+1.66}\right)\right]^{-1}
$$


Where $\tau_{\mathrm{o}-\mathrm{Ps}}$ is the life time of ortho-positronium in $\mathrm{ns}, \mathrm{R}$ is the average radii of free volume holes in the samples [16].

Table 2. The average radii $(\mathrm{nm})$ of free volume holes in the crystalline and amporphous domains of PP and its nanocomposites as determined by PALS.

\begin{tabular}{|l|l|l|}
\hline Sample & Crystalline domain & Amorphous domain \\
\hline $\mathrm{PP}$ & $0.206 \pm 0.003$ & $0.325 \pm 0.004$ \\
\hline $\mathrm{PP} / \mathrm{MMT}(1 \%)$ & $0.204 \pm 0.003$ & $0.327 \pm 0.003$ \\
\hline $\mathrm{PP} / \gamma-\mathrm{PP}(20 \%)$ & $0.238 \pm 0.023$ & $0.333 \pm 0.008$ \\
\hline $\mathrm{PP} / \gamma-\mathrm{PP}(20 \%) / \mathrm{MMT}(1 \%)$ & $0.215 \pm 0.023$ & $0.323 \pm 0.008$ \\
\hline
\end{tabular}

As seen from this table when nonpolar PP is mixed with gamma-irradiated polar PP, the free volume hole sizes increase in both crystalline and amorphous domains. However introduction of $1 \%$ of MMT to this binary blend causes reduction in free volume hole sizes in both domains. Compatibilizing action of irradiated PP is seen by comparing the hole radia of PP and $\mathrm{PP} / \gamma-\mathrm{PP}(20 \%) / \mathrm{MMT}(1 \%)$, they are almost the same.

\section{Characterization by $X R D$}

For structural characterization of PP nanocomposites X-Ray diffractograms were recorded for the $2 \theta$ region of $2-8^{\circ}$ as show in Figure 4 . From the $2 \theta=6,8^{\circ}$ corresponding to maximum

intensity of pure MMT, d-spacing was calculated to be $1.3 \mathrm{~nm}$ for the MMT used in this study. The peak due to MMT is clearly seen to remain in the diffractogram of PP/MMT blend. The d-spacing calculated for this peak shifted to around $7^{\circ}$ with an interlayer distance of $1.36 \mathrm{~nm}$ indicating that the formation of microcomposites only. When gamma-irradiated PP was introduced to this binary blend the peak corresponding to crystalline structure of MMT disappeared and shifted to lower angles indicating separation of silicate layers by the diffusion of low molecular weight polar PP into MMT structure. The extent of this separation was calculated form the displaced peak positions in Fig.4 and collected in Table 3. The XRD results show that radiation degraded/oxidized PP can therefore be considered to function as a compatibilizer between unmodifiedMMT and PP. 


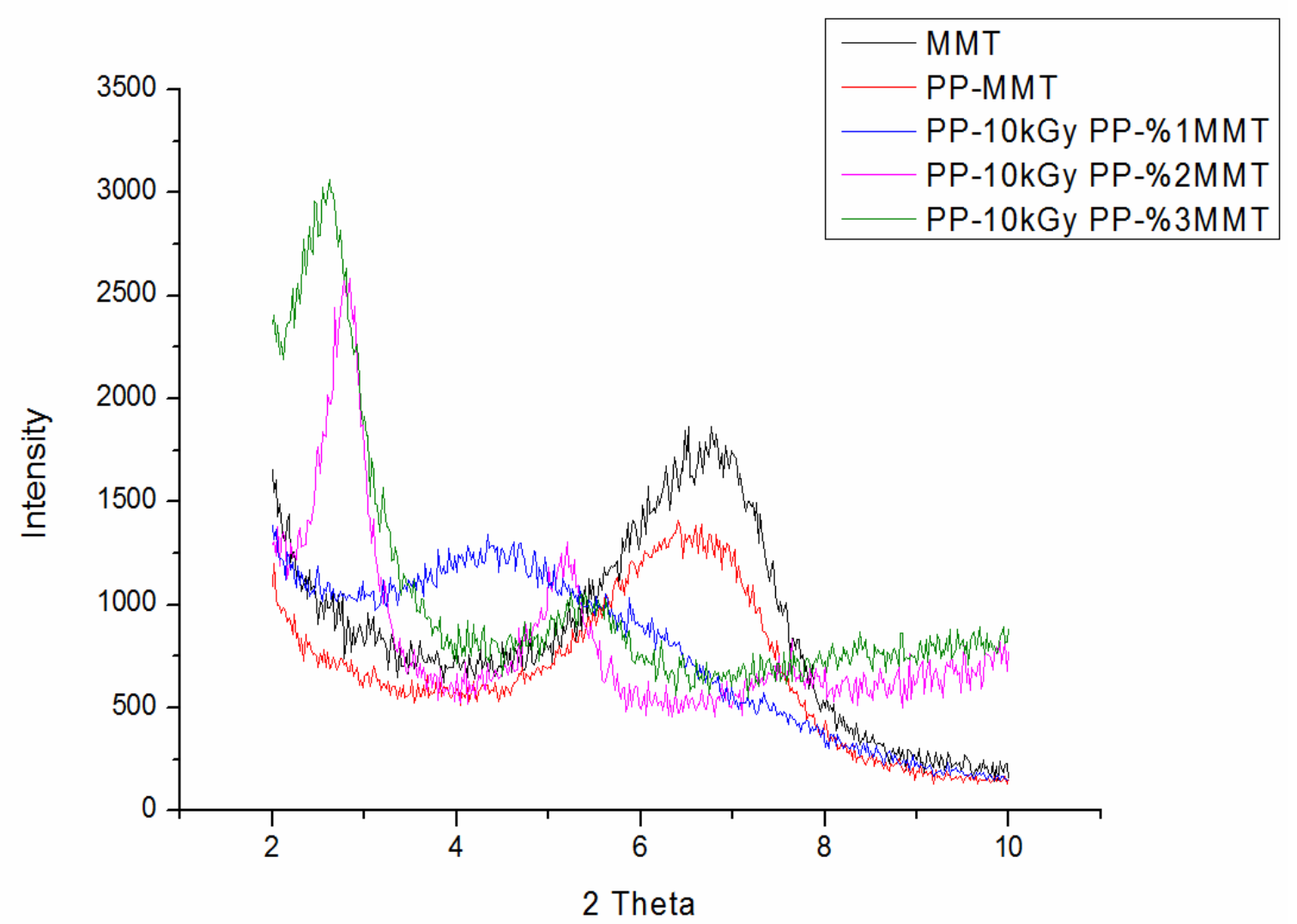

Figure 4. XRD diffractograms of MMT, PP-MMT and three nanocomposites prepared by using gamma irradiated PP.

Table 3. d-spacing values of MMT, PP-MMT microcomposite and nanocomposites calculated from the respective XRD diffractograms.

\begin{tabular}{|c|c|c|c|c|c|}
\hline & MMT & PP-MMT & $\begin{array}{c}\text { PP-10 kGy PP- } \\
\text { \%1 MMT }\end{array}$ & $\begin{array}{c}\text { PP-10 kGy PP- } \\
\text { \%2 MMT }\end{array}$ & $\begin{array}{c}\text { PP-10 kGy PP- } \\
\text { \%3 MMT }\end{array}$ \\
\hline 2-theta & $6,80^{\circ}$ & $6,60^{\circ}$ & $4,21^{\circ}$ & $2,90^{\circ}$ & $2,62^{\circ}$ \\
\hline $\mathrm{d}_{\text {spacing }}(\mathrm{nm})$ & 1,30 & 1,36 & 2,22 & 2,98 & 3,11 \\
\hline
\end{tabular}




\section{TEM results}

TEM image of PP-MMT microcomposite as shown in Fig.5a clearly demonstrates that bulk structure of MMT particles are retained in the blend in conformity with the XRD diffractogram given in Fig.4.
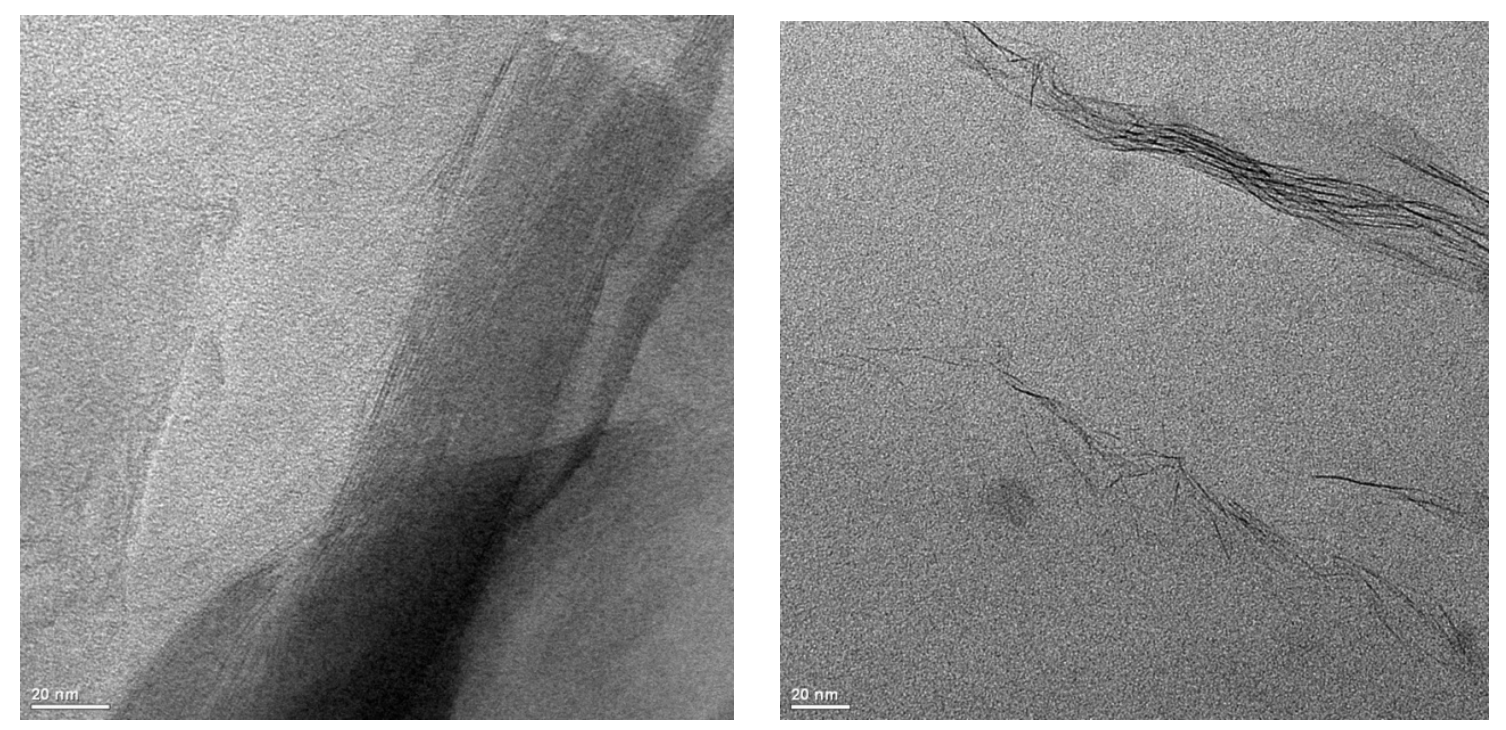

Fig. 5 a, b. TEM images of PP-MMT microcomposite and PP-10 kGy PP-\%1 MMT nanocomposites.
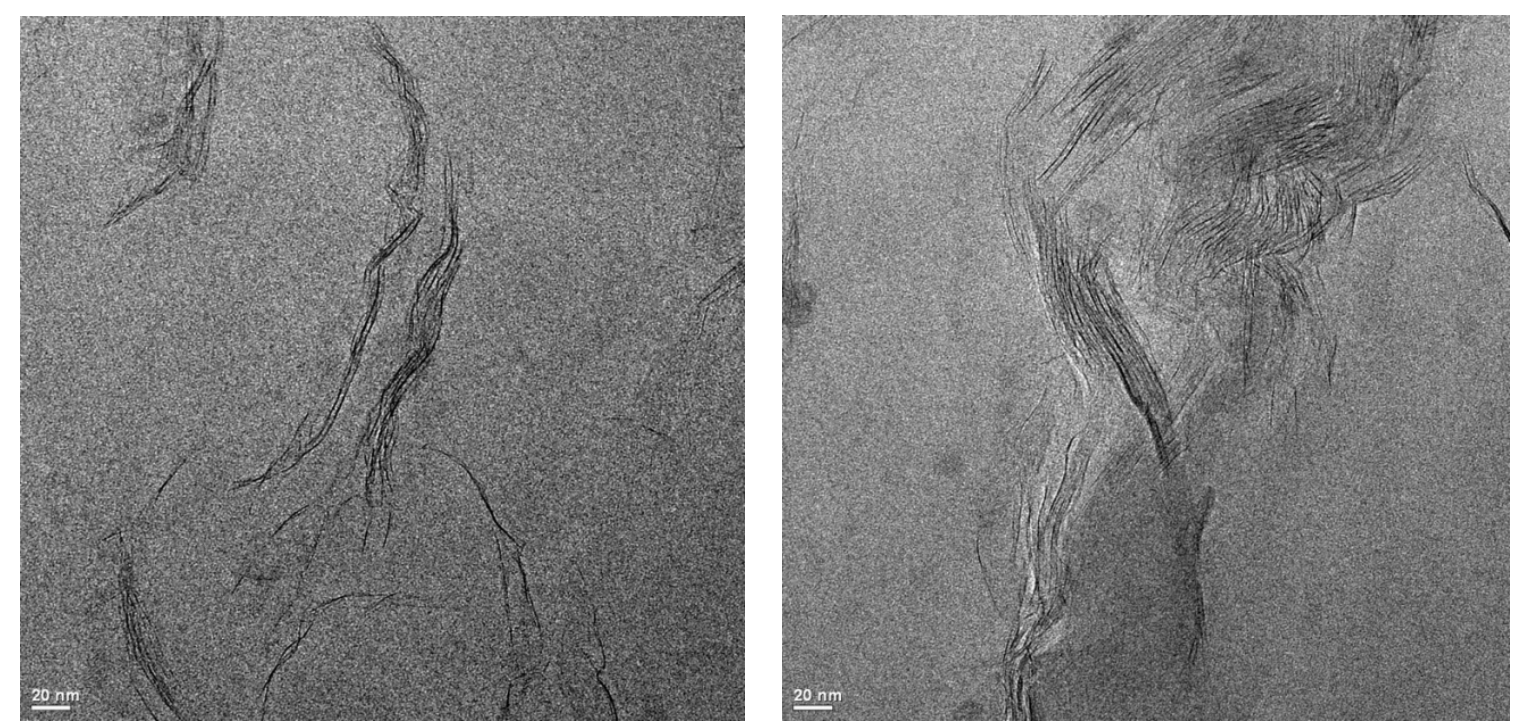

Fig. 5c, d. TEM images of PP-10 kGy PP-\%2 MMT and PP-10 kGy PP-\%3 MMT nanocomposites. 
In Figure 5 b,c,d, TEM images of nanocomposites prepared by using 20\% 10kGy irradiated PP loaded with 1,2, and 3\% MMT respectively are given. The separation of silicate layers are clearly visible in all three compositions of MMT. Although some individual silicate layers can be distinguished indicating exfoliation, MMT structure is mostly intercalated by gammairradiated PP chains. Since intercalation does not destroy the crystalline structure of MMT completely, some ordered layers are retained as seen in these figures. These observations are in perfect accordance with the XRD diffractograms of these three nanocomposites as some diffraction patterns at very low angles were found to be remaining. TEM results support those obtained by XRD measurements both indicating the formation of exfoliated/intercalated clay structure in the nanocomposite.

\section{SAXS Analysis}

In SAXS studies first of all small q (Guiner) region was evaluated and the data collected was fitted to the equation given below by Glatter ve Kratky [17] for plate form(2D) nano aggregations in the samples.

$I(q)=A\left(\frac{2 \pi}{q^{2}}\right)\left(\Delta \rho^{2}\right) T^{2} e^{-q^{2} R t^{2}}$

Where $\mathrm{I}(\mathrm{q})$ is defined as scattering intensity; $\mathrm{q}$ is the magnitude of the scattering vector; $\Delta \rho$ is electron density difference and A,T and Rt are the coefficients related to the number of nano aggregations, formation thickness and average size of nano aggregations, respectively.

Using Matcad program, appropriate parameter values were determined for start-up and then IGOR package program was used in the refinement process. (IGOR Pro,1988-2008 WaveMetrics, Inc. All Rights Reserved, P. O. Box 2088/Lake Oswego, Oregon 97035/USA).

When the nano aggregations in a sample increase, the maximum scattering intensity in the SAXS pattern increases accordingly [18]. As seen in Fig. 6, the maximum scattering intensity is the highest at $1 \%$ addition of MMT, in other words, the most nano size dispersion was observed at $1 \%$ addition. As the addition MMT increased, a gradual decrease in maximum scattering intensity was observed. 


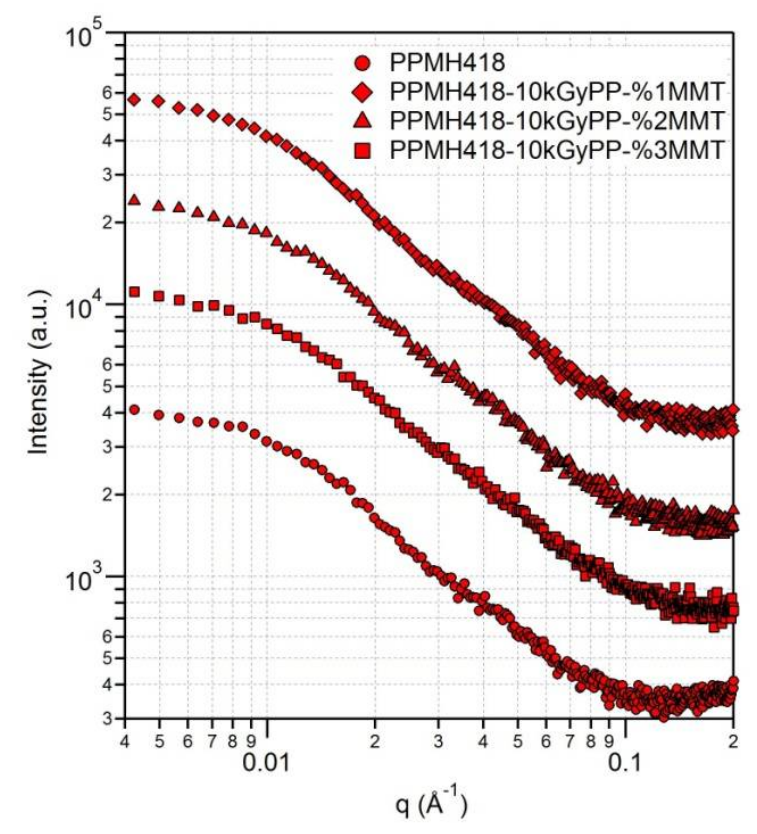

Fig. 6. SAXS patterns of PP and the nanocomposites

In scattering experiments, X-rays give a scattering pattern sensitive to electron density difference in the sample. The gradual decrease in the maximum scattering intensity indicates that the electron density difference within the nano-aggregation is decreasing. This can only be explained by the fact that the crystalline structure of the clay is weakened by diffusing of polymer chains homogeneously in between the silicate layers.

Fig. 7 shows the conformity of the SAXS data with fit function. In Table 4 fit parameters are collected that are defined by fit functions. As can be seen from this Table as the addition of MMT increases the parameter values decrease. Background refers to irregular scattering in the sample. This irregular scattering is due to the non-uniformity of the polymer film surface and the irregularities in the inner interface. In the presence of irradiated PP the crystalline structure of the clay is gradually and homogeneously dispersed in the polymer matrix to form a more uniform structure and the scattering due to the amorphous part of semi-crystalline polypropylene is reduced. The most important indication of enhanced distribution of MMT into the polymer structure is the decrease in electron density difference. The average size (Rt) and the thickness $(\mathrm{T})$ of the silicate nano particles are also reduced by the diffusion of irradiated PP into the layers of MMT. 

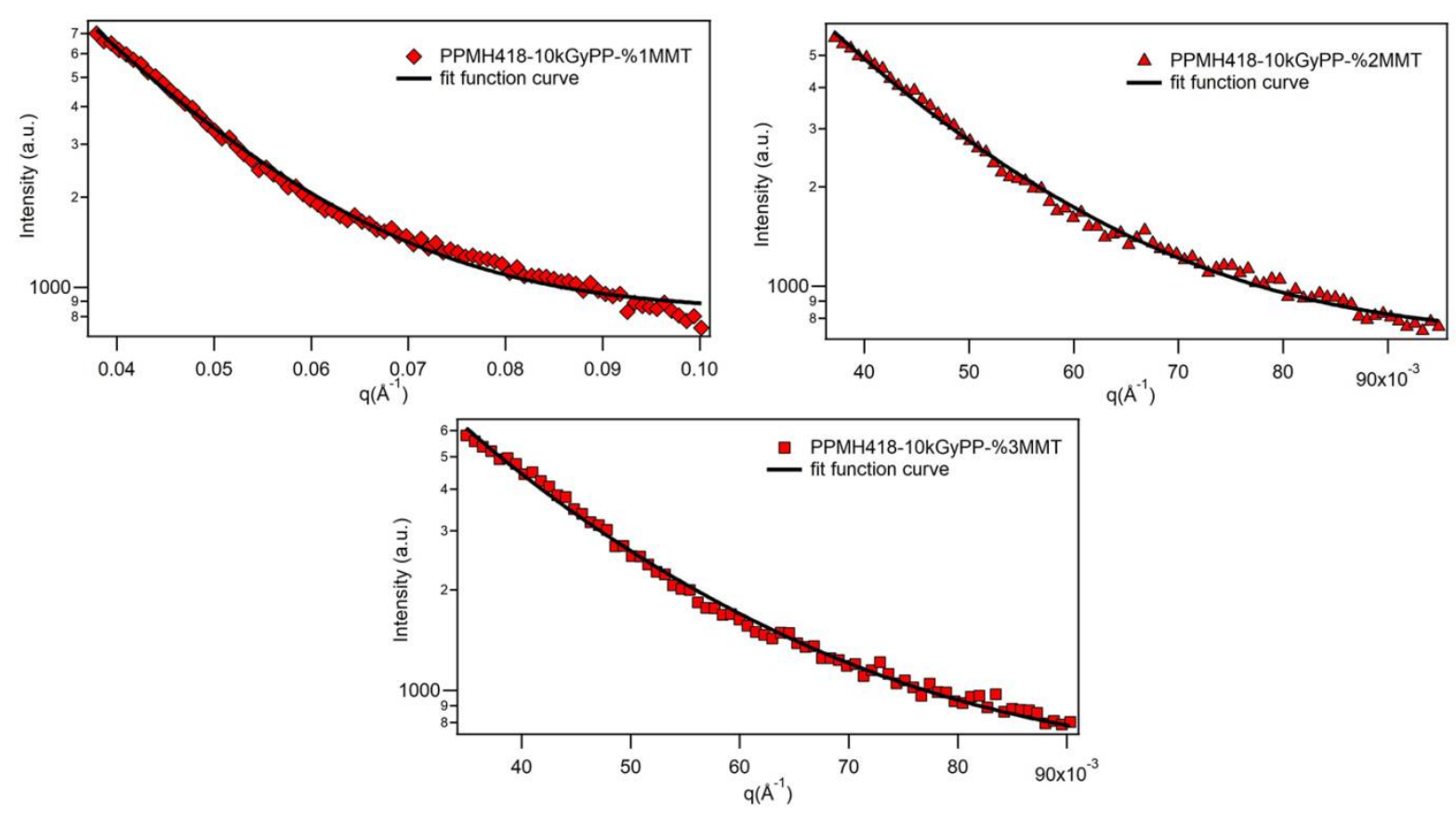

Fig.7. The conformity of the fit function and SAXS data in 0.04-0.10 q range.

Table 4. The fit parameters found in the IGOR package program.

\begin{tabular}{|l|l|l|l|l|}
\hline \multicolumn{1}{|c|}{ PP nanocomposites } & Background & $\begin{array}{c}\Delta \rho \\
\left(\text { el./ } \AA^{3}\right)\end{array}$ & T(nm) & Rt(nm) \\
\hline PP-10kGyPP-\%1MMT & $835.8 \pm 1.6$ & $0.33 \pm 0.03$ & $3.78 \pm 0.41$ & $1.84 \pm 0.03$ \\
\hline PP-10kGyPP-\%2MMT & $700.7 \pm 4.2$ & $0.32 \pm 0.02$ & $3.67 \pm 0.35$ & $1.72 \pm 0.04$ \\
\hline PP-10kGyPP-\%3MMT & $612.4 \pm 6.0$ & $0.31 \pm 0.04$ & $3.59 \pm 0.24$ & $1.51 \pm 0.09$ \\
\hline
\end{tabular}

With the SAXS analysis, it has been found that in the range of 1-3\% clay addition, the nano aggregations are distributed at the molecular level in the polymer matrix by the formation of more homogeneous structure.

\section{CONCLUSIONS}

As anticipated PP irradiated with gamma rays causing extensive chain scission determined by MFR measurements and oxidation shown by FTIR spectroscopy imparted the necessary size 
and affinity properties to original PP to act as a compatibilizer for the preparation of PP-MMT nanocomposites. XRD and TEM measurements confirmed the separation of silicate layers to accommodate irradiated PP in the mixture of unmodified MMT and pristine PP. Additional information collected from PALS and SAXS studies were in support of these findings. The compatibility introduced between the PP and MMT by using radiation degraded/oxidized eventually showed better mechanical properties in terms of elastic modulus and tensile strength.

The authors confirm no conflict of interests.

\section{REFERENCES}

1. Pavlidou, S; Papaspyrides, C.D. A review on polymer-layered silicate nanocomposites. Prog. Polym. Scien., 2008, 33, 1119-1198.

2. Kato, M; Matsushita, M; Fukumori, K. Development of a new production method for a polypropylen-clay nanocomposite. Polym. Eng. Scien., 2004, 44, 1205-1211.

3. Pfaendner, R. Nanocomposites: Industrial opportunity or challenge? Polym. Deg. Stab. 2010, 98, 369-373.

4. Kim, D. H; Fasulo, P.D; Rodgers, W.R; Paul, D.R. Structure and properties of polypropylene-based nanocomposites: Effect of PP-g-MA to organoclay ratio. Polymer, 2007, 48, 5308-5323.

5. Yuan, W; Guo, M; Miao, Z; Liu, Y. Influence of MA grafted PP on the dispersion of clay in PP/clay nanocomposites. Polym. J. 2010, 42, 245-251.

6. Kotal, M; Bhowmick, A.K. Polymer nanocomposites from modified clays: Recent advances and challenges. Prog. Polym. Scien., 2015, 51, 127-187.

7. Marchant, D; Jayaraman, K. Strategies for optimizing polypropylene-clay nanocomposite structure. Ind. Eng. Chem. Res. 2002, 41, 6402-6408.

8. Minoura, Y; Ueda, M; Mizuuma, S., Oba, M. The reactions of polypropylene with maleic anhydride. J. Appl. Polym. Scien. 1969, 13, 1625-1630. 
9. Thakur, V; Leuteritz, A; Gohs, U; Kretzschmer, B; Wagenknecht, U; Bhowmick, A.K; Heinrich, G. Montmorillonite nanocomposites with electron-beam modified atactic polypropylene. Appl. Clay Scien., 2010, 49, 200-204.

10. Çağlayan, T; Güven, O. Preparation and characteriation of poly(ethylene-vinyl acetate)-based nanocomposites using radiation-modified montmorillonite. Rad. Phys. Chem., 2018, http://doi.org/10.1016/j.radphyschem

11. Rivaton, A; Lalande, D; Gardette, J.L. Influence of the structure on the $\gamma$-irradiation of polypropylene and on the post-irradiation effects. Nucl. Inst. Meth. Phys. Res. B, 2004, 222, 187-200.

12. Chen, B; Evans, J.R.G; Greenwell, H.C; Boulet, P; Coveney, P.V; Bowden, A.A; Whiting, A. A critical appraisal of polymer-clay nanocomposites. Chem. Soc. Rev., 2008, 37, 568-574.

13. Dole, M. Radiation chemistry of macromolecules. Academic Press, New York, 1973, Volume I, pp 4-25.

14. Walzak, M.J; Flynn, S; Foerch, R; Hill, J.M.; Karbashewski, E; Lin, A; Strobel, M. $U V$ and ozone treatment of polypropylene and poly(ethylene terephthalate). J. Adhes. Scien. Technol. 1995, 9, 1229-1248.

15. Sharma, S.K; Pujari, P.K. Role of free volüme characterisitcs of polymer matrix in bulk physical properties of polymer nanocomposites: A review of positron annihilation lifetime studies. Prog. Polym. Scien., 2017,75, 31-47.

16. Eldrup, M; Pedersen, N.J; Sherwood, J.N. Positron anihilation study of defects in succininitrile. Phys. Rev. Lett., 1979, 43, 1407-1410.

17. Glatter, O; Kratky, O. Small angle X-ray Scattering. Academic Press Inc. Ltd., London, 1973, pp35-36.

18. Privalko, V. P; Karaman, V. M; Privalko, E. G; Walter, R; Friedrich, K; Zhang, M. Q; Rong, M. Z. Structure and thermoelasticity of irradiation grafted nano-inorganic particle filled polypropylene composites in the solid state. J. Macromol. Sci. Physics, 2002, B41, 487-505. 